\section{International Registration of Cultivar Names for Unassigned Woody Genera Mar. 2013-Nov. 2016}

\author{
Stefan B. Lura and Alan T. Whittemore ${ }^{1}$ \\ U.S. National Arboretum, 3501 New York Avenue NE, Washington, DC \\ 20002
}

In Mar. 2013, the delegated authority of the International Cultivar Registration Authority (ICRA) for cultivars of unassigned woody genera held by the American Public Gardens Association was transferred from the Brooklyn Botanic Garden to the U.S. National Arboretum in Washington, DC. Since that time, two woody genera formerly treated by this ICRA have been reassigned their own ICRAs, whereas two more genera were transferred to the ICRA for unassigned genera on the retirement of their registrars. Authority for registrations in the genus Cercis was transferred from this ICRA to the U.S. National Arboretum in Washington, DC, USA in 2013. Likewise, Stewartia was assigned to a new ICRA in 2016; requests for registrations in that genus may be referred to the Polly Hill Arboretum in Martha's Vineyard, MA, USA. Registration authority for cultivars of Hydrangea and Amelanchier transferred back to the ICRA for unassigned woody genera on the retirement of their registrars in early 2014 and Summer 2016, respectively.

Between Mar. 2013 and Nov. 2016, a total of 29 cultivar epithets were registered. Most are registrations of new or newly documented cultivar epithets, but five involve the acceptance and registration of epithets for relatively well-established cultivars in an effort to stabilize their nomenclature. Some of these names do not yet have standard specimens. We are working to obtain good herbarium specimens for many of these cultivars, and standards will be designated when we have suitable material.

Prospective registrants are encouraged to contact the registrar to request a registration form. For contact details and for a list of genera that have been approved for registration with this ICRA, please see the main contact page for the American Public Gardens Association at http://www.ishs.org/sci/ icralist/3.htm. A full listing of genera covered by international registration authorities may be accessed at http://www.ishs.org/sci/taxlist/ taxlist.htm.

Aucuba japonica 'Petite Jade'. Registered on 18 Dec. 2013. Registrant: Scott Aker, U.S. National Arboretum, 3501 New

Received for publication 12 Mar. 2018. Accepted for publication 11 May 2018.

${ }^{1}$ Corresponding author. E-mail: Alan.Whittemore@ ars.usda.gov.
York Ave. NE, Washington, DC 20002, USA. Aucuba japonica 'Petite Jade' (NA 55288; PI-668405) originated from cuttings collected from Chollipo Botanical Garden, Chungcheongnam-do, South Korea, in 1984. The plant was grown for many years in the U.S. National Arboretum's Introduction Garden and was sent to nurseries for evaluation in 2002. It was released in Oct. 2013. It differs from other cultivars of the species in its compact, rounded habit. It is an evergreen, slow-growing, compact shrub with mounded form and dense branching, reaching 6 feet in height in 30 years. Its new growth is shiny and bright green aging to dark green. It is a female with half-inch-long, oblong fruits that ripen to medium red in late autumn when pollinated by a male clone. It is known to be adapted to USDA Hardiness Zones 6-10.

Clethra alnifolia 'Firefly'. Registered on 12 Feb. 2014. Registrant: Dr. Margaret Pooler, U.S. National Arboretum, 3501 New York Ave. NE, Washington, DC 20002, USA. Clethra alnifolia 'Firefly' (NA 73935; PI-663907) originated within the U.S. National Arboretum's landscape plant breeding program in McMinnville, TN, under the direction of Dr. Sandra Reed. It is the first Clethra introduction from that program and the second from the U.S. National Arboretum. It was selected from a second-generation seedling population derived from a C. alnifolia 'Tom's Compact' ('Compacta', nom. inval.) $\times$ 'Ruby Spice' controlled hybridization that was made in 1998. It was released in Oct. 2011. Its foliage is bright yellow in full sun and limegreen in full shade, although it is not recommended for full sun in warmer areas of its adaptation as foliage may scorch in hot summer weather. It is a small, deciduous shrub with rounded growth habit, reaching 3 feet tall and 3 feet wide at 5 years. In midsummer, 'Firefly' produces 3-inch panicles of fragrant white flowers, but it does not flower as profusely as green-foliaged cultivars. It is known to be adapted to USDA Hardiness Zones 4-8.

Deutzia ×rosea 'Nikko Blush'. Registered on 12 Feb. 2014. Registrant: Dr. Margaret Pooler, U.S. National Arboretum, 3501 New York Ave. NE, Washington, DC 20002, USA. Deutzia $\times$ rosea 'Nikko Blush' (NA 74356; PI-669442) originated from a controlled cross made by Ruth Dix at the U.S. National Arboretum in 1987 between Deutzia gracilis 'Nikko' and Deutzia $\times$ rosea 'Carminea' with the intent of creating a pink-flowering selection that had the appealing compact growth habit of 'Nikko'. About 18 seedlings resulted from this cross, and propagules of three were sent for evaluation in 2005. The best clone was released as 'Nikko Blush' in Nov. 2013. This cultivar was selected for its abundant, pink-blushed flowers and flower buds that appear in late spring, contrasting with medium-green foliage on a low-mounded, somewhat spreading shrub with arching branches. The plant grows 3 feet high and 4.5 feet wide after 4 years in Washington, DC. Its pink-blushed flowers appear in profusion in late April to early May and are mildly fragrant, and its leaves are fine textured, medium green, and willow like. It is known to be adapted to USDA Hardiness Zones 5-8.

The following six epithets were registered on 7 Aug. 2014 for cultivars of Elaeagnus angustifolia L. by Mostafa Assadi, Botanical Department, Research Institute of Forests and Rangelands, P.O. Box 13185-116, Tehran, Iran. These cultivars are expected to be described in more detail in an upcoming publication by the registrant. Although these cultivars have been selected and cultivated primarily for their edible fruit rather than their ornamental value, which is traditionally the primary focus of the ICRA for Unassigned Woody Genera, they occur within a denomination class that is both governed by this ICRA and commonly cultivated for ornamental use. The method of propagation (by seed or cloning) is not known to the registrant.

Elaeagnus angustifolia 'Anabi'. Fruits are oblong to broadly elliptic, fruit diameter being about equal over the entire length, 1.2$2 \mathrm{~cm}$ long and $0.8-1.8 \mathrm{~cm}$ wide, and brown in color. The fruit skin is not farinose and is glabrous or with only sparse peltate scales; the skin is not easily separated from the fruit flesh. The flavor is somewhat sweet (less sweet than 'Shekari', listed in the following paragraph.) The name 'Anabi' indicates a similarity to the fruits of Ziziphus spinachristi (L.) Desf. Synonym: 'Keshmeshi', meaning "raisin." Nomenclatural standard: Iran, Isfahan prov., Isfahan, Kaveh street, Emamzadeh Ghasem, 1670 m, 2 Nov. 2009, M. Janighorban \& M. Feyzi 15283 (TARI).

Elaeagnus angustifolia 'Churuk'. Fruits are ovate, narrowing from the base toward the apex, $1.5-2.5 \mathrm{~cm}$ long and $0.7-1.4 \mathrm{~cm}$ wide, light brown to yellowish (to orange-red) in color with distinct transverse wrinkles. The fruit skin is white-farinose with dense peltate scales and separates easily from the fruit flesh. The flavor of the fruit is not considered to be as good as that of some other cultivars. Nomenclatural standard: Iran, Markazi p., Arak to Shzand road, Chopoghli park, 1755 m, 22 Oct. 2010, M. Janighorban \& M. Feyzi 15318 (TARI).

Elaeagnus angustifolia 'Khormai'. Fruits are ovate, narrowed toward the apex, 1.4-3.3 $\mathrm{cm}$ long and 1-2 $\mathrm{cm}$ wide, dark or light reddish-brown (date-brown), and smooth in profile, lacking wrinkles. The fruit skin is 
glossy and nearly glabrous with very sparse peltate scales and separates easily from the fruit flesh (a "slipskin" form). The fruit is sweet and softer than 'Churuk' (the preceding listing), which it resembles in fruit shape. Nomenclatural standard: Iran, Zanjan Province, between Zanjan and Mianeh, climatology station, $1700 \mathrm{~m}, 23$ Oct. 2010, M. Janighorban 15307 (TARI).

Elaeagnus angustifolia 'Kolahi'. Fruits are oblong or elliptic to globular, usually roughly equal in diameter over the entire length (similar in shape to 'Anabi', listed previously), $1.3-3 \mathrm{~cm}$ long and $0.8-2 \mathrm{~cm}$ wide, date-brown to yellow-olive in color. The fruit skin is nearly glabrous or with sparse to dense peltate scales and separates very easily from the fruit flesh. The name, which means "hat," is a reference to the ease with which the fruit skin is removed, i.e., as easily as a hat may be taken off. Nomenclatural standard: Iran, Hamadan Province, between Hamadan and Malayer, 2100 m, 31 Oct. 2009, M. Janighorban \& M. Feyzi 15303 (TARI).

Elaeagnus angustifolia 'Shekari'. Fruits are elliptic globular to globular, 1-2 cm long and $0.7-1.8 \mathrm{~cm}$ wide, light brown or yellowolive in color. The fruit skin, which is not easily separated from the flesh, is farinose and sparsely to densely covered with peltate scales that give it the appearance of being dusted with sugar, which is the meaning of the name 'Shekari'. Local synonyms in different parts of Iran include 'Noghli' and 'Shirin'. Nomenclatural standard: Iran, Isfahan Province, Isfahan, Kaveh street, Emamzadeh Ghasem, 1670 m, 2 Nov. 2009, M. Janighorban \& M. Feyzi 15283 (TARI).

Elaeagnus angustifolia 'Shurei'. Fruits are elliptic or elongated elliptic, narrowed only at the tip, $1-1.2 \mathrm{~cm}$ long and $0.8-1.5$ $\mathrm{cm}$ wide, and dark brown in color. The fruit skin, which separates easily from the flesh, is farinose and is densely covered with white peltate scales. The flavor of the fruit is not considered to be as good as that of some other cultivars. Nomenclatural standard: Iran, Isfahan Province, Ardestan road, Dizeloo, 1750 m, 24 Oct. 2009, M. Janighorban 15292 (TARI).

Gymnocladus dioicus 'Little Joe'. Registered on 24 May 2016. Registrant: Joe McNally, Iowa Arboretum, Inc., 1875 Peach Ave., Madrid, IA 50156, USA (Iowa Arboretum Accession 850089). This cultivar is a compact, multistemmed cultivar of $G$. dioicus. Its registered epithet is a partial play on words: "Little" refers to the plant size and habit and "Joe" is a slang word for coffee, in reference to the species' common name of Kentucky coffee tree. This cultivar grows at a rate of $7-15 \mathrm{~cm}$ per year, compared with an average growth rate of the species of $30-40 \mathrm{~cm}$ per year. The leaves are $40 \mathrm{~cm}$ long $\times 30 \mathrm{~cm}$ wide, $\approx 1 / 3-1 / 2$ of the size that is typical for the species ( $90 \mathrm{~cm}$ long $\times 60 \mathrm{~cm}$ wide). Gymnocladus dioicus 'Little Joe' has a low ascending branching pattern, resulting in a multitrunked plant, with no single leader present. The leaves keep a slightly darker blue-green color throughout the growing season, even in hot summer conditions, when compared with typical plants of the species. This plant was procured by root cuttings from a mature specimen plant located on private property formerly owned by Reginald Martin, located at 1729 Marble Road, Union, IA. Mr. Martin (now deceased) indicated that they had been planted, before 1977 , by a previous owner; the original source is unknown. This cultivar tolerates drought and wet soils and is adapted to USDA hardiness zones 3-8. Synonym: G. dioicus 'Nana' (an invalid name under which this cultivar was being grown during its distribution and evaluation phase from propagations of 850089A.)

Hydrangea quercifolia 'Queen of Hearts'. Registered on 28 Aug. 2014. Registrant: Dr. Margaret Pooler, U.S. National Arboretum, 3501 New York Ave. NE, Washington, DC 20002, USA. Hydrangea quercifolia 'Queen of Hearts' (NA 79748; PI668118) originated within the U.S. National Arboretum's landscape plant breeding program in McMinnville, TN, by Dr. Sandra Reed. It is the third oakleaf hydrangea cultivar released from this program, following 'Ruby Slippers' and 'Munchkin' and was selected from the same seedling population that produced 'Ruby Slippers'. It originated from F2 progeny of full-sibling crosses of F1 hybrid seedlings, which had themselves been obtained by controlled hybridization of oakleaf hydrangea cultivars 'Flemygea' (SNOW QUEEN) and 'Pee Wee'. It was released in Oct. 2013. 'Queen of Hearts' was selected for its large, upright inflorescences and heavy flowering. It flowers $\approx 7-$ $10 \mathrm{~d}$ later than standard oakleaf hydrangea cultivars, and inflorescences remain attractive after those of other cultivars have faded. The plant is a medium, rounded shrub that grows 6.5 feet tall and 9 feet wide at 10 years. Its leaves are dark green in summer and mahogany-red in fall. In early summer, 'Queen of Hearts' is covered with 9-inchlong inflorescences that are held upright above the foliage. Flowers open white and then slowly age to a deep pink color. It is known to be adapted to USDA Hardiness Zones 5-8.

Hypericum 'Rowallane'. Registered on 15 Jan. 2014. Registrant: Dr. E. Charles Nelson, Tippitiwitchet Cottage, Hall Road, Outwell, Wisbech PE14 8PE, Norfolk, UK. Hypericum 'Rowallane' originated as a chance seedling of hybrid origin (the putative parents are Hypericum leschenaultii Choisy and an unknown cultivar of Hypericum hookerianum Wight \& Arnott) in the garden of Rowallane House, Saintfield, County Down, Northern Ireland, which was first propagated and marketed in the 1930s. (For its history, see W. F. Walsh and E. C. Nelson, 1987. An Irish Florilegium II. London. Plate 41, pp. 178-180; E. C. Nelson and E. Deane, 1993. 'Glory of Donard'. A History of the Slieve Donard Nursery, Newcastle, County Down. Belfast. pp. 74-75; E. C. Nelson, 2000. A Heritage of Beauty. The Garden Plants of Ireland. Dublin. pp. 116-117.)
Hypericum 'Rowallane' is a shrub reaching $2-3 \mathrm{~m}$ in height, with long, arching stems. Its leaves, usually deciduous in Ireland, are elliptical, $\approx 7.5 \mathrm{~cm}$ long, $3 \mathrm{~cm}$ broad, glabrous, dark green on the upper surface and paler beneath. Its flowers are borne at the tips of the main stems and side shoots, either in groups of three or singly; they are shallowly cup shaped, $\approx 7 \mathrm{~cm}$ in diameter, with five petals deep golden yellow in color, each petal obovate with a slightly crinkled margin, lacking glands; each stamen fascicle contains as many as 90 golden yellow stamens; central capsule was ovoid, green, and $\approx 1 \mathrm{~cm}$ long. The watercolor painting by Wendy F. Walsh, from a plant growing in Rowallane, published in An Irish Florilegium II (Plate 41) is here designated as the standard.

The earliest published account of this plant, an undated nursery flier issued by the Slieve Donard Nursery after the Spring of 1938 (reproduced in facsimile in Nelson 2000: 116), used the name 'Rowallane Hybrid'. That was also the name used when the cultivar was granted an Award of Merit by the Royal Horticultural Society (RHS) in 1943 (Gardeners' chronicle 2: 126. 1943). However, in common usage (since the early 1950s) the name has been shortened to 'Rowallane'. Nelson and Deane (1993: 178) noted that shortening of a cultivar name was contrary to Article 31 of the then-current (1980) edition of the International Code of Nomenclature for Cultivated Plants (ICNCP), and so they used 'Rowallane Hybrid' in their account of the Slieve Donard Nursery. 'Rowallane Variety', cited in example 25 of Article 17 in the seventh edition (2004), and repeated as example 29 of Article 21 of the eighth and ninth editions $(2009,2016)$ of the ICNCP, is an inadvertent error; that name cannot be traced in horticultural or botanical sources and so was not established, as stated in the example, by being published before 1959 .

It is required under Article 29.2 of the ICNCP (ninth edition 2016) to accept the name that best preserves existing usage, so the name 'Rowallane' is here chosen as the accepted name for this widely grown cultivar.

Loropetalum chinense var. chinense 'Snow Panda'. Registered on 12 Feb. 2014. Registrant: Dr. Margaret Pooler, U.S. National Arboretum, 3501 New York Ave. NE, Washington, DC 20002, USA. Loropetalum chinense var. chinense 'Snow Panda' (NA 75507; PI-660659) originated from seeds collected near Yan Chi He, Hubei Province, China, in 1994 by members of the North America-China Plant Exploration Consortium with collection number WD121. It was selected in 2006 in cooperation with Monrovia Growers in Visalia, CA, and propagated for further evaluation and was introduced in May 2011. It was selected for its abundant white flowers, medium-green foliage, and loosely vase-shaped habit with arching branches. In 15 years, the plant grew 10 feet high and 8.5 feet wide in Washington, 
DC. It is known to be adapted to USDA Hardiness Zones 7-9.

Nyssa sinensis 'Jim Russell'. Registered on 26 Jan. 2015. Registrant: Joke Osselaer, Arboretum Wespelaar, Grote Baan 63, 3150 Haacht (Wespelaar), Belgium. Nyssa sinensis 'Jim Russell' (Wespelaar accession number 92007) is named after Jim (James) Russell (1920-96), plantsman and advisor to the late George Howard and the Castle Howard Estate near York (North Yorkshire, UK) from 1968-92, creator of the garden in Ray Wood and the Yorkshire Arboretum at Castle Howard. He donated this tree, which came from Fromefield Nursery (Romsey, Hampshire), to Arboretum Wespelaar where it entered the collection in 1992. Philippe de Spoelberch of Arboretum Wespelaar selected this tree in 2000 because of its beautiful upright habit and magnificent autumn coloring. It is a vigorous, upright ascending tree; $N$. sinensis usually forms an erratic, somewhat messy and bushy plant in contrast to this selection. The leaves of the selection are slightly bigger and some leaves achieved autumn color in summer, earlier than those of typical $N$. sinensis in Belgium.

Nyssa sinensis 'Jim Russell' has grown to a height $8 \mathrm{~m}$ and spread $6 \mathrm{~m}$, with a trunk circumference of $77 \mathrm{~cm}$ at breast height $(1.5 \mathrm{~m})$, in 23 years. In spring, the new leaves have a beautiful bronze to oxblood red color [RHS Color Chart (CC) 183C = Oxblood Red to $187 \mathrm{~B}]$. They turn green (RHS CC 137A, C) and yellow-green (RHS 144A = Lettuce Green) when they mature. The elliptic, acute, and entire leaves are $9.5-18 \mathrm{~cm}$ long and 5$6.5 \mathrm{~cm}$ at their broadest point (sometimes below the middle and sometimes above the middle). The petiole is $2.5-3.5 \mathrm{~cm}$ long. Nyssa sinensis 'Jim Russell' is renowned for its magnificent but very late autumn color, which peaks during the first half of November and varies from yellow to deep red from year to year. The senescing leaves have been measured in the following colors: orange-red group RHS CC 30A (Nasturtium Red) + 33A (Poppy)/34A, B; grayed orange RHS CC 167B-169A, C; yellow-orange RHS CC 23A (Cadmium Orange), and red RHS CC 46B (Scarlet Red-Union Jack Red). The small, inconspicuous flowers are light green (RHS CC 142B = Agathia Green). They appear in May to June and are mostly male with 5-10 stamens in two alternate whorls around a nectariferous disk and clustered in racemes or umbels. The young bark is smooth and gray brown (RHS CC 199D). When the tree is aging, the bark starts to crack in small rectangular platelets at the base of the trunk. The twigs are brown to yellow-brown (RHS 165B $=$ almond shell), with scattered lenticels. The young bark is smooth and gray brown (RHS CC 199D). When the tree matures, the bark starts to crack in small, rectangular platelets at the base of the trunk. The twigs are brown to yellow-brown (RHS 165B = almond shell), with scattered lenticels.

Nyssa sinensis 'Jim Russell' loves rainy summers but is also happy in dry, warm summers; it prefers acidic soil and should not be planted on chalk. It is hardy in Belgium to USDA Hardiness Zones 7-8, although it can suffer minor winter branch dieback as a young plant but becomes fully hardy later. The tree is propagated by grafting. It earned an Award of Garden Merit from the RHS in 2013.

Philadelphus 'Koloss'. Registered on 12 Nov. 2015. Registrant: Sergey Loktev, Barybino, Moscow Oblast, Russia. This cultivar originated as a chance, open-pollinated seedling that appeared in the registrant's garden in 2009; it was first observed in 2011 and was selected for its unique characteristics in 2012. It has grown to a height of $3.3 \mathrm{~m}$ and a spread of $2 \mathrm{~m}$ after 6 years, with a maximum recorded shoot diameter of $3 \mathrm{~cm}$. Its young shoots are reddish-green and pubescent. Leaves are mid-green, lighter on the underside, lanceolate with a rounded base and pointed tip, slightly serrate margins, and with sparse pubescence on both sides; the petiole is $0.5 \mathrm{~cm}$ long. Inflorescence length is up to $11 \mathrm{~cm}$, bearing seven to nine flowers per inflorescence; flower form is single, up to $3.5 \mathrm{~cm}$ in diameter; petals are white, slightly tinted cream, oval; stamens $\approx 30$ per flower; fragrance strength is medium. The flowering occurs from the beginning to the end of the typical Philadelphus season in the vicinity of Moscow, with the duration from first flower opening to the fading of the last flower up to $30 \mathrm{~d}$.

Philadelphus 'Moscow Snowflake'. Registered on 12 Nov. 2015. Registrant: Sergey Loktev, Barybino, Moscow Oblast, Russia. This cultivar originated as a chance, openpollinated seedling that appeared in the registrant's garden in 2009; it was first observed in 2011 and was selected for its unique characteristics in 2012. It has grown to a height of $2 \mathrm{~m}$ and spread of $3.5 \mathrm{~m}$ after 6 years, with a maximum recorded shoot diameter of $3 \mathrm{~cm}$. Its young shoots are light green and glabrous. The leaves are light green, lighter on the underside, elongate, with serrate margins; the petiole is $1 \mathrm{~cm}$ long. The inflorescence is up to $7 \mathrm{~cm}$, bearing five to seven flowers per inflorescence; the flowers are single, up to $4 \mathrm{~cm}$ in diameter, with rounded, slightly waved petals; petals are white, slightly tinted yellowish, rounded, with slightly undulate margins; stamens $\approx 35$ per flower; fragrance is slight. The flowering season is early to very late, with the duration from first flower opening to the fading of the last flower up to $20 \mathrm{~d}$.

Prunus campanulata 'Abigail Adams'. Registered on 12 Feb. 2014. Registrant: Dr. Margaret Pooler, U.S. National Arboretum, 3501 New York Ave. NE, Washington, DC 20002, USA. Prunus campanulata 'Abigail Adams' (NA 69013; PI-667657) is a doubleflowered form of $P$. campanulata that was first observed by U.S. National Arboretum botanist Roland Jefferson during a 1986 collecting trip to Taiwan. At Jefferson's request, scions were sent to the United States by the Chinese Culture University, Yang-Ming-Shan, Taipei, Taiwan, in 1987. Since then, this accession has been used in multiple crosses in the flowering cherry breeding program at the
U.S. National Arboretum. This cultivar was released in June 2013 primarily to make this genetic resource available to growers and breeders. The outstanding feature of this germplasm is its dark pink, semidouble flowers that are pollen fertile, thus facilitating its use in breeding. It may also be valuable for its early bloom, low chilling requirement, and its adaptation to warmer climates. Its abundantly produced flowers are dark pink and semidouble, each with 15-20 petals and 5-10 functional stamens. This plant has not been tested in the field, so data on growth rate, habit, and landscape performance are not yet available. The species grows to 25 feet tall and wide and is one of the earliest blooming of the flowering cherries. It is known to be adapted to USDA Hardiness Zones 8-9.

Prunus 'Helen Taft'. Registered on 12 Feb. 2014. Registrant: Dr. Margaret Pooler, U.S. National Arboretum, 3501 New York Ave. NE, Washington, DC 20002, USA. Prunus 'Helen Taft' (NA 61128; PI664076) resulted from a controlled hybridization made in 1981 between Prunus $\times$ yedoensis and $P$. campanulata under the direction of Dr. Donald Egolf. The seed parent came from a cutting of an original Washington, DC Tidal Basin tree that was planted in 1912 during a ceremony by the Japanese Ambassador's wife, Viscountess Iwa Chinda, and U.S. First Lady Helen Herron Taft. 'Helen Taft' was released in Mar. 2012 in commemoration of the 100th anniversary of the planting of the cherry trees around the Tidal Basin in Washington, DC. The name recognizes the role that former First Lady Helen Taft played in this historic planting. The plant forms an upright tree with a spreading crown, growing 35 feet tall and 30 feet wide in 30 years. Its foliage is medium green, turning pale yellow to red in the fall. It blooms just before $P$. xyedoensis with abundant, large, pale pink single flowers that turn darker in the centers as the flowers mature. It is known to be adapted to USDA Hardiness Zones 6-8.

Styrax japonicus 'Spring Showers'. Registered on 12 Feb. 2014. Registrant: Dr. Margaret Pooler, U.S. National Arboretum, 3501 New York Ave. NE, Washington, DC 20002, USA. Styrax japonicus 'Spring Showers' (NA 71587; PI-660970) was selected from an open-pollinated seedling population in 2000 and was released in Feb. 2011. It is the first Japanese snowbell cultivar to be released from the U.S. National Arboretum's landscape plant breeding program in McMinnville, TN. Its delayed budbreak allows it to be successfully grown in areas frequently subject to late spring freezes. This cultivar forms a small tree with tight conical habit, reaching 12 feet tall and 8 feet wide at 10 years. Its foliage is lustrous dark green in summer and light yellow in fall, and it emerges 2-3 weeks later than most standard cultivars. In late spring, 'Spring Showers' is covered with $3 / 4$ inch diameter, fragrant, white flowers that are suspended below the foliage. It is known to be adapted to USDA Hardiness Zones 5-8. 
Tecoma 'Albert C. Pomar'. Registered on 15 Sept. 2015. Registrant: Kenneth A Pomar, Saint Augustine, FL, USA. This cultivar is an F1 seedling from a controlled cross between Tecoma garrocha, the seed parent, and Tecoma stans performed by the registrant in 2014. The plant, which is a sprawling shrub of rapid growth, had reached a height of $75 \mathrm{~cm}$ and a spread of $60 \mathrm{~cm}$ at an age of 14 months. It has glossy medium-green leaves and the stems are speckled when mature. The flowers are borne in large clusters (or sprays) with the shape of $T$. garrocha but the size of $T$. stans and are golden yellow with an orange flush toward their centers. The plant is named for the registrant's father (deceased). The hybrid is not particular as to soil type and prefers part to full sun; its cold hardiness is unknown.

Viburnum rhytidophyllum 'Cree'. Registered on 12 Feb. 2014. Registrant: Dr. Margaret Pooler, U.S. National Arboretum, 3501 New York Ave. NE, Washington, DC 20002, USA. Viburnum rhytidophyllum 'Cree' (NA 62293; PI-583788) is a seedling selection grown from open-pollinated seed collected from a plant that originated from wild-collected seed (NA 49608) brought to the United States by Theodore Dudley in 1980 as part of the Sino-American Botanical Expedition (SABE). The mother plant from which the original seed was collected was found in the Shennongjia Forest District, Western Hubei Province, China, at an elevation of $\approx 2100 \mathrm{~m}$. 'Cree' was initially selected for replicated field trials by D. R. Egolf in 1989. It was named and released by G. R. Johnson, former National Arboretum scientist, in 1994. This cultivar was selected primarily for its somewhat slower growth rate and more compact size compared with typical $V$. rhytidophyllum, as well as for its superior dark evergreen foliage, excellent cold hardiness, and good flowering and fruiting. It is a relatively compact shrub that has reached a height of $2.6 \mathrm{~m}$ and a width of $2.4 \mathrm{~m}$ in 13 years of growth in Washington, DC. The foliage is dark green on the upper surface and yellow-green beneath. White flowers occur in clusters; inflorescences are 8-10 $\mathrm{cm}$ in diameter and appear in mid-May in Washington, DC. Fruit ripen from red to black. The plant is known to be adapted to USDA Hardiness Zones 5-8; it has proven to be reliably evergreen in zone 6 and may prove evergreen in zone 5.

Viburnum 'Nantucket'. Registered on 12 Feb. 2014. Registrant: Dr. Margaret Pooler, U.S. National Arboretum, 3501 New York Ave. NE, Washington, DC 20002, USA. Viburnum 'Nantucket' (NA 69852; PI651840) was selected in 1999 and released in 2008. It originated with a cross of $V$. 'Eskimo' $\times$ Viburnum macrocephalum $\mathrm{f}$. keteleeri made in 1988 by the late Donald Egolf. The female parent, 'Eskimo', was derived from open-pollinated seed from the cross [(Viburnum carlesii $\times$ Viburnum $\times$ carlcephalum $) \times$ Viburnum utile $]$. The male parent came from wild-collected seeds from
Zhejiang Province, China, which was collected in 1980 by T. Dudley as part of the SABE. 'Nantucket' is the 20th viburnum cultivar released from the National Arboretum's shrub breeding program. It was selected for its large, mildly fragrant, abundant, branched white inflorescences that cover the plant in spring, its dark semievergreen narrow leaves, and its upright, relatively compact growth habit. It grows 12 feet tall and 7 feet wide in 16 years and bears pure white, lightly fragrant flowers in abundant, 4- to 5-inch, branched inflorescences in May. It is cold-hardy in USDA Zones 6-8.

Vitex 'Daniel Searle'. Registered on 19 Oct. 2015. Registrant: Andrew Bell, Chicago Botanic Garden, 1000 Lake Cook Road, Glencoe, IL 60022, USA. Vitex 'Daniel Searle' originated as a partially controlled cross between Vitex rotundifolia, the seed parent, and Vitex agnus-castus. The cross was performed as part of a breeding project by Kris Jarantoski at Chicago Botanic Garden; control was affected by isolation of the parent material. The texture of this clone is refined, with mostly compound foliage, similar to that of $V$. agnus-castus. Profuse spikes of lilac flowers are produced on the current season's growth in early to mid-August. The plant reaches a height of $1.8 \mathrm{~m}(6 \mathrm{ft})$ and a spread of $1.2-1.5 \mathrm{~m}(4-5 \mathrm{ft})$ by the end of the growing season in Chicago, following either spring pruning or cold injury. It is cold-hardy to USDA Hardiness Zone $5 \mathrm{~b}\left(-10\right.$ to $\left.-15^{\circ} \mathrm{F}\right)$ and is propagated by cuttings. It has been named in honor of a member of the board of the Chicago Horticultural Society and is being introduced through Chicagoland Grows Inc., Glencoe, IL.

Vitex 'Helen V. Froelich'. Registered on 19 Oct. 2015. Registrant: Andrew Bell, Chicago Botanic Garden, 1000 Lake Cook Road, Glencoe, IL 60022, USA. Vitex 'Helen V. Froelich' originated as a partially controlled cross between $V$. rotundifolia, the seed parent, and $V$. agnus-castus. The cross was performed as part of a breeding by Kris Jarantoski at Chicago Botanic Garden; control was affected by isolation of the parent material. The foliage of 'Helen V. Froelich' is similar to that of $V$. rotundifolia, with occasional lobed or compound leaves. It produces lilac-colored flowers. The plant reaches a height of $1.5-1.8 \mathrm{~m}(5-6 \mathrm{ft})$ and a spread of $1.5-1.8 \mathrm{~m}(5-6 \mathrm{ft})$ by the end of the growing season in Chicago, following either spring pruning or cold injury. It is coldhardy to USDA Hardiness Zone $5 b$ ( -10 to $-15^{\circ} \mathrm{F}$ ) and is propagated by cuttings. It has been named in honor of a member of the board of the Chicago Horticultural Society and is being introduced through Chicagoland Grows Inc.

Wisteria floribunda 'Alba'. Registered on 28 May 2015. Registrant: Dr. James Compton, Tisbury, Wiltshire, UK. Wisteria floribunda 'Alba' derives its name from the correct name under the botanical code, $W$. floribunda f. alba (Carrière) Rehder \& E. H. Wilson. The basionym, Wisteria multijuga var. alba, was published by E. A. Carrière in 1891. According to Carrière, it had been introduced to France by P. \& E. Transon Brothers, Orleans. This white-flowered cultivar of $W$. floribunda is known by many names, and Dr. Peter Valder in his book Wisterias: A Comprehensive Guide (Portland, OR: Timber Press, 1995) proposed recommending acceptance of the epithet 'Shiro Noda' on the basis of its widespread use in Japan and the fact that the name Wisteria sinensis 'Alba' [based on $W$. sinensis f. alba (Lindl.) Rehder \& E. H. Wilson 1916] was in earlier use. However, $W$. floribunda 'Alba' is more widely and frequently used today than any of its synonyms worldwide and has been in more widespread, continuous use over the past 100 years than any other epithet. The abandonment of this cultivar epithet in favor of 'Shiro Noda' would also break with the majority of horticultural literature over the past century. 'Shiro Noda' (which itself merely means "white $W$. floribunda" in Japanese) should probably be interpreted as a description, not a formal name for a cultivar. Most importantly, ICNCP Articles 21.7 and 31.6 provide that a Latin-form cultivar epithet such as 'Alba' that was used for different species within the same genus before 1959 should not have another name accepted in its place, provided that both epithets are also the correct final epithets for their respective taxa under the botanical code. It is, however, necessary to cite the full botanical name along with the cultivar epithet whenever referring to $W$. floribunda 'Alba' or $W$. sinensis 'Alba', to avoid any ambiguity.

In keeping with the reasoning outlined previously, $W$. floribunda 'Alba' is accepted and registered, and the following epithets are to be treated as synonyms: 'Longissima Alba', 'Multijuga Alba', 'Shiro Naga', 'Shiro Noda', 'Shirobana', 'Showa Shiro', 'Snow Showers', and 'Wase Shiro Naga'. Nomenclatural standard: Japan (Kanagawa Prefecture, Yokohama): grounds of Yokohama Nursery Co., 27 Apr. 1914, E. H. Wilson 6581 (A).

Wisteria floribunda 'Kuchibeni'. Registered on 5 June 2015. Registrant: Dr. James Compton, Tisbury, Wiltshire, UK. According to the registrant, this old Japanese cultivar was first listed as $W$. sinensis rubra and later $W$. floribunda 'Carnea' by its introducer in the West, W. B. Clarke of San Jose, CA. It has been listed and grown occasionally under a variety of different names and designations, including 'Carnea', 'Alborosea', 'Akebono', 'Peaches and Cream', and LIPSTICK. However, none of its early names gained especially widespread popularity, and it is almost always grown today under its traditional Japanese name 'Kuchibeni'. As such, the epithet 'Kuchibeni' is here designated as accepted according to ICNCP Article 29.2 and Recommendation 29A. The English translation of this epithet is "lipstick," and because it seems to have been published later and is a translation of a name in another 
language, LIPSTICK may only be applied as a trade designation (ICNCP, Article 32 Note 1).

Wisteria floribunda 'Rosea'. Registered on 28 May 2015. Registrant: Dr. James Compton, Tisbury, Wiltshire, UK. Wisteria floribunda 'Rosea' derives its name from the correct name under the botanical code, $W$. floribunda f. rosea (Bean) Rehder \& E. H. Wilson. The basionym, Wistaria multijuga var. rosea, was published by W. J. Bean (Trees and Shrubs Hardy in the British Isles. Ed. 1. 2: 683. 1914. London, J. Murray). According to Bean (Trees and Shrubs Hardy in the British Isles. Ed. 8. 4: 753. 1980. London, J. Murray), it was introduced in 1903, which is the year of its first unambiguous published reference (L. Beissner, E. Schelle, and H. Zabel, Handbuch der Laubholz-Benennung. P. 269. Berlin: P. Parey, 1903), where it was listed as Wistaria polystachia multijuga rosea Hort. However, earlier references to "Wistaria rosea" (W. W. Valk, Hort. \& J. Rural Art Rural Taste 3 (2):66. 1848, and L. F. Dietrich. Encyklopädie der gesammten niederen und höheren Gartenkunst. P. 1012, 1860. Leipzig: Arnoldische Buchhandlung.) might refer to this plant. Wisteria floribunda 'Rosea' is today grown under several names, most notably its synonym 'Honbeni'. Dr. Peter Valder in his book Wisterias: a comprehensive guide (Portland, OR: Timber Press, 1995) proposed acceptance of the epithet 'Honbeni' instead, suggesting on largely theoretical grounds that the name 'Rosea' may have always been a confused name. However, the available literature suggests otherwise; W. floribunda 'Rosea' is used more commonly than any of its synonyms worldwide and has been in longer continuous use than any other epithet, and there is no evidence that 'Rosea' has actually been widely confused in its application. The bar for considering replacement of a popular and well-established epithet because of confused use must always be set very high to prevent unnecessary destabilization of the nomenclature.

In arguing for the acceptance of 'Honbeni' over 'Rosea' for this clone, Valder suggested that because Rehder and Wilson were themselves unaware of the existence of more than one pink-flowered clone when they described $W$. floribunda f. rosea, we cannot be certain today which one they were describing. However, the body of literary evidence indicates that the name 'Rosea' has been applied to a single, widespread clone that agrees with the fairly specific description by Rehder and E. H. Wilson, and this provides evidence that the name has been consistently applied. The abandonment of this epithet in favor of 'Honbeni' would also break with most western horticultural literature; before Peter Valder's Wisterias was published in 1995, this cultivar was nearly always cited as $W$. floribunda 'Rosea'. Valder witnessed the epithet rosea being used by some nurserymen in Japan for the very pale lavender form known in the West as 'Kuchibeni', but because the cultivar is reasonably well defined and otherwise used consistently, this is best treated as a minor case of misapplication. Because the final epithet of the correct name under the botanical code is to be retained when that taxon is treated as a cultivar (ICNCP Art. 21.5), unless Article 29.2 is found to supersede it with its requirement to register the name that best preserves existing usage - and with the reasonable certainty that the cultivar to which this epithet is generally applied is the very same one described as $W$. floribunda f. rosea (Bean) Rehder \& E. H. Wilson-W. floribunda 'Rosea' is accepted and registered and the following epithets are to be treated as its synonyms: 'Honbeni', 'Beni' ('Beni Fuji', nom. illeg.), and 'Pink Ice'. See Valder (op. cit.) for a discussion of additional, lesser known epithets that might also be referred to 'Rosea'. Nomenclatural standard: Japan [Kanagawa Prefecture, Yokohama]: grounds of Yokohama Nursery Co., 27 Apr. 1914, E. H. Wilson 6578 (A).

Wisteria floribunda 'Violacea Plena'. Registered on 1 July 2015. Registrant: Dr. James Compton, Tisbury, Wiltshire, UK. The clone most widely known today as $W$. floribunda 'Violacea Plena' was first described in printed literature as $W$. sinensis flore pleno by E. A. Carrière in 1878 , although according to C. S. Sargent it had been introduced from Japan to the United States as early as 1862 , and is thought to have entered Europe from there. It was published as $W$. sinensis var. violaceo-plena by C. K. Schneider in 1907, and this was the basis for the new combination $W$. floribunda forma violaceo-plena (C. K. Schneid.) Rehder \& E. H. Wilson published in 1916. However, the variety was called "violacea-plena" and "violacea plena" in horticultural works printed at least as early as 1917 (C. S. Sargent, Bull. Popular Inform. Arnold Arbor. n. s. 3(8): 31. 1917; also printed in The National Nurseryman 25 (3): 244.1917 and elsewhere without crediting Sargent), and 'Violacea Plena' then became the common spelling for the cultivar epithet.

This cultivar is also sometimes listed under the epithets 'Yae-kokuryu' and 'Black Dragon'. It was also occasionally listed as 'Flore-pleno' or 'Flore Pleno' but is seldom found under that name today. 'Black Dragon', which is now easily the name most commonly used for this cultivar outside of Japan, is a confused name; it is evidently a mistranslation of 'Yae-kokuryu', which actually translates into English as "double black dragon." Meanwhile, "black dragon" is the correct translation of 'Kokuryu', a synonym for a distinct, single-flowered cultivar that is correctly known as 'Royal Purple'. The name 'Black Dragon' is to be rejected as a cultivar epithet because of its confused use and its status as a translation of another epithet; because it is associated with more than one cultivar, it should not be used as a trade designation unless it is coupled with a correct cultivar name. Confusion and inconsistency in the application of these two names has likely led in recent years the mistaken impression that 'Yae-kokuryu' is now the most widely used name for 'Violacea Plena'; on closer examination of nurseries supposedly carrying this cultivar, it is evident that this is only because it has been treated by the RHS Plant Finder in synonymy with the misleading and badly confused epithet 'Black Dragon', which is used by more United Kingdom nurseries than either 'Violacea Plena' or 'Yae-kokuryu' but listed by the RHS Plant Finder only under the name they chose to accept, 'Yae-kokuryu'. In fact, some of the nurseries listed as supposedly selling the double-flowered cultivar were selling the single-flowered 'Royal Purple' under the name 'Black Dragon'. See Peter Valder's treatment in Wisterias: A Comprehensive Guide (Portland, OR: Timber Press, 1995) for a complete discussion of additional epithets that have been occasionally applied to this cultivar but are not in common usage today and seldom appear in print

Because the epithet 'Violacea Plena' has been so pervasively used for this cultivar for so many years, and taking into consideration the problems associated with the use with its synonyms, $W$. floribunda 'Violacea Plena' is here accepted and registered according to Article 29.2 of the $I C N C P$, which stipulates that "the name that best preserves existing usage is to be chosen as the accepted name by the appropriate ICRA without regard to any rank in which those epithets might have been established or to the principle of priority." The name 'Violacea Plena' does not have priority based on the correct name under the botanical code, but it has been in continuous use for $\approx 100$ years as this cultivar's most common epithet. The epithet based on the correct name under the botanical code, 'Flore-pleno', has been used little as a cultivar epithet, if at all. Nomenclatural standard: Revue Horticole, serié 4, vol. 59: [t. opposite p. 564] (1887) [Godard].

Wisteria sinensis 'Prolific'. Registered on 10 June 2014. Registrant: Dr. James Compton, Tisbury, Wiltshire, UK. Wisteria sinensis 'Prolific' was first published as a cultivar name by H. J. Grootendorst in Dendroflora 5: 63-64. 1968 with a brief description and illustration. Although its origin was not identified at the time, this name has come to be applied almost universally in modern horticulture to the most widespread clone of the species, which is also widely considered to represent the first clone of this species introduced to Europe. It is also considered to be the clone from which the scientific name $W$. sinensis was described. It is distinguished from other clones of the species by its higher number of flowers per raceme and more abundant production of racemes.

Shortly after John Sims (Bot. Mag. 46: t. 2083. 1819) formally described Glycine sinensis, J. C. Loudoun published the name Wisteria consequana (Gardener's Magazine 2: 422. 1827) for this species in honor of the Cantonese merchant whose garden 
supplied the clone, his name being anglicized as Consequa. Loudoun's new name was superfluous and thus illegitimate under the botanical code, and the name $W$. sinensis (Sims) DC. has been used ever since, but Dr. Peter Valder in his 1995 book Wisterias: A Comprehensive Guide proposed that the cultivar name 'Consequa' be given to this clone in honor of the same Cantonese merchant.
Dr. Valder misinterpreted the name 'Prolific' because he had seen $W$. floribunda material mislabeled with this name, and he did not realize that the two names are based on the same clone, so they must be considered synonymous.

In attempting to stabilize the nomenclature of this cultivar, 'Prolific' is chosen here as the accepted name for this widespread and well-characterized clone, with 'Consequa' as its later synonym, in accordance with Article 29.2 of the ICNCP. The article directs that the name best preserving existing usage must be chosen by the registrar whenever two or more names are in use, and 'Prolific' is currently in widespread use, whereas 'Consequa' is hardly used at all. Nomenclatural standard: Curtis's Botanical Magazine 46: t. 2083 (1819) [J. Curtis]. 